\title{
Şeriyye Sicillerine Göre Hicri 1137 (1724-25) Yılı İstan- bul'unda Osmanlı Konutu / Menzili
}

\author{
Ottoman House (Dwelling) in Istanbul According to Ottoman
} Court Records in 1724-25

\section{Hüseyin Necdet Ertuğ}

\section{Öz}

Konut (menzil) insan yaşamındaki barınma ihtiyacının karşılanmasını sağlamaya yönelik en temel ihtiyaçlardan biridir. Konut tarzları ve tarihsel süreç içerisinde meydana gelen yapısal değişiklikler bir kültürün yaşama bakışının hikâyesini de ifade eder.

Osmanlı dönemi söz konusu olduğunda özellikle sanat tarihi ve mimarlık çalışmalarında yeterince çalışma olmakla birlikte, bugün artık mevcut olmayan konutlar ve onları oluşturan ana bölümlerin tarihsel alandaki örneklerinin nicelik ve nitelikleri hakkında daha az bilgi mevcuttur. Şeriyye sicillerindeki mülk satışlarıyla alakalı hüccetlerde yer alan konut tasvirleri eksik olan bilgileri kısmen tamamlamaktadır. Bu sebeple 1724-1725 yılında İstanbul Suriçi ile Eyüp ve Hasköy bölgeleri çalısmanın merkezi olmuş ve kaynak olarak üç sicilde (İstanbul Şeriyye Sicilleri: 2/135, 7/124, 7/125) yer alan mülk satışları kullanılmıştır. Sonuç olarak incelenen dönemdeki Osmanlı konutu ile sanat tarihçilerinin tarihsel konut tipolojileri ilişkisi ortaya konulabilmiştir.

Anahtar Kelimeler: Osmanlı Evi, Mimari, Emlak, Yerleșim Tarihi Doç. Dr., Sakarya Üniversitesi, Fen Edebiyat Fakültesi, Felsefe Bölümü, nertug@sakar-
ya.edu.tr

Bu makale iThenticate sistemi tarafından taranmıştır.

Makale gönderim tarihi: 25.03.2015

DOİ: $10.17550 /$ aid.38853 


\section{Abstract}

Dwelling has been very important in people's lives because of the need of protection from the outside world. House styles and the structural changes occur in historical process tells the story about the worldview of a culture. Given this, while looking at the history of these houses we can also see the history of the culture.

Houses are not only made for protection from cold and hot, but also they serve as shelter for private life. Every culture has created its own home style. Therefore the signs of human culture can be followed by looking at the history of home they lived in.

In regard to the Ottoman era, alot of studies about this topic can be found at different fields especially in the history of art and architecture.

Unfortunetely the information about the buildings that do not exist anymore are mostly theoretical. The house descriptions appear in the documents related with property sales in court records can be considered as the complement for the missing information. Given this, Istabul Suriçi, Eyüp and Hasköy areas in 1724-1725 are chosen as the focus of this study and property sales in three records (Istanbul Court Records: 2/135, 7/124, 7/125) are used as source. As a result, in this study the relationship between the Ottoman house in the related period and the historical house typologies set forth by the art historians is tried to be shown.

Keywords: Ottoman House, Architecture, Real Estate, History of Dwelling. 
Konut -daha geniş anlamda ikametgâh-, ilk zamanlardan bugüne değin insan yaşamının en asli ihtiyaçlarından birisidir. Barınma ve sığınak olmanın ötesinde kültürel bir damga olarak insanlığa ait olan birikimin izlerini konut üzerinden de sürmek mümkündür. İnsanın, yapıp etmeleri söz konusu olduğunda ulusların ve çağların birikimlerindeki yaratıcılık ve tevarüs olunan geleneği bizzat konutlarında ortaya koymaya çalışmaları, gelenek ve yeniyi bir arada sergilemeleri sadece insana özgüdür.

Osmanlı toplumunun uzun asırlara yayılan konut mimarisinin somut delillerinden geriye pek az şey kalmıştır. Konut geleneğinin kendisi şimdiye kadar yapılan çalışmalarla aşağı yukarı tahmin olunabilirse de zaman ve mekânlara ait kesin verilerle desteklenerek bilimselleştirilmesi için uğraşılar devam etmektedir. Osmanlı dönemi söz konusu olduğunda sivil mimari kaynaklarına hele, yapım aşamaları, planları gibi teferruata 20. asra kadar rastlamak neredeyse mümkün değildir. Resmi ve sıradan olmayan saray, köşk, kasır, cami, han, kervansaray gibi yapılar hakkında ise malumat oldukça fazladır. ${ }^{1}$ Osmanlı konutunu ele alan çalışmalarda mimarlar, sanat tarihçileri ve tarihçiler aynı konuyu farklı üsluplarla ele almakta; tarihsel olan pek çok çalışmaya ise tabii olarak şeriyye sicilleri esas olmaktadır. ${ }^{2}$

Türk konut tipolojisi üzerine -kendisinden önce başka çalışmalar bulunmakla birlikte- ${ }^{3}$ derli toplu en önemli yayın Sedad Hakk1

1 18. yüzyıl Osmanlı mimarisinde Batı etkilerinin incelendiği bir eserde kasırlar, saraylar, türbe ve çeşme gibi daha umumi yapılar ele alınmaktadır (Ayda Arel, Onsekizinci Yüzyıl İstanbul Mimarisinde Batılılaşma Süreci, (İstanbul, 1975).

2 Bir bölgenin belli bir tarihteki sicilinin incelenerek göreli ölçütlere göre sosyal hayat başlığı altında yapılmış pek çok tez bulunmaktadır. Bu tip çalışmalara örnek için bkz. Ali Çolak, "1868 nolu Trabzon Şeriyye Siciline Göre Kentin Sosyal ve Ekonomik Hayatı (1703-1705)”, (Yüksek Lisans Tezi, KTÜ 1997; M. Faruk Karacaoğlu, "17651768 Yılları Arasında Konya'da Sosyal ve Ekonomik Hayat, (59 Numaralı Konya Şer'iye Siciline Göre)", (Yüksek Lisans Tezi, Selçuk Üniversitesi 2008). Daha mütemmim bir çalışma için ayrıca bkz. Suraiya Faroqhi, Men of Modest Substance, House Owners and House Property in Seventeenth-Century Ankara And Kayseri, (Cambridge University Press, 2002).

3 Albert Gabriel, “Türk Evi”, Arkitekt Dergisi 5-6 (1938): 149-154; Celal Esad, Türk Sanatı, (İstanbul, 1928); Nureddin İbrahim, "Yeni Ankara'da Eski Türk Evleri" Yeni Kitab, 9 (1928): 28-32. 
Eldem'in Türk Evi'dir. ${ }^{4}$ Eldem bu eserinde Türk konutunu sofasız, diş sofalı, orta sofalı ve köşe sofalı olarak ayrımlamıştır ki sofa sayısı ve tipleri oda sayısını da belirlemektedir. ${ }^{5}$ Osmanlı konutu ilk zamanlarda zeminden 1.5, 2 metre yüksekte başlayan tek katlı evler iken zamanla kat sayısı artmıştır. Kat sayısı ne olursa olsun, alt katlar en üst katı taşıyan kısımlardır. Genelleme yapılamasa da katlar bugün anlaşıldığı gibi birbiriyle aynı yükseklikte olmayabilir ki zemin üstü katlar bir çeşit ara kat olup üst kata göre daha az yüksektir. ${ }^{6}$ Osmanlı konutunun belirleyici özelliklerinden birisi de sicillerdeki örneklerde görüldüğü üzere avlulu oluşudur. ${ }^{7}$ Bir başka özellik yapının üst katlarındaki çıkmalardır ki bunlar cumba, çıkartma ve bazen şahnişin, köşk, cihannüma olarak isimlendirilmektedir. ${ }^{8}$ Konutlar temel kısımları dışında tamamen ahşaptan olup çok kısa süre içinde inşa edilebilmektedir. ${ }^{9}$ Bu sebeple

4 Sedad Hakkı Eldem, Türk Evi Osmanlı Dönemi, 1 (İstanbul, 1984). Bununla birlikte Doğan Kuban Türk konutunu oda, eyvan ve revak galerilerin esas olduğu avlunun merkeze alındığı plan şekillerine göre tasnif etmiştir. Yalnız temel olarak her iki görüşün birbirine paralel olduğu söylenebilir (Doğan Kuban, Türk Hayat'lı Evi, (Eren Yayıncılık, 2013).

5 Eldem'in tipolojisinin söz konusu edildiği bir kaç çalışmaya örnek olarak bkz. Uğur Tuztaşı, "Koruma ve Tarihsel Açıdan İdealleş[-tiril-]miş “Türk Evi”nin Arkeolojisi: Osmanlı Evinin Fragmanları ve Tipolojik Elemanları", (Doktora Tezi, Mimar Sinan Güzel Sanatlar Üniversitesi 2009); Ceren Sarıalioğlu, "Historiyografik Bir Sorunsal Olarak: "Türk Evi” (1928-1995)", (Yüksek Lisans Tezi, Yıldız Teknik Üniversitesi 2008); Maurice Cerasi, "The Formation of Ottoman House Types: A Comparative Study in Interaction with Neighboring Cultures", Muqarnas, 15 (1998): 116-156.

6 Eldem, Türk Evi, 16, 17.

71751 tarihinde inşa edilmiş ve bugüne kadar kısmen de olsa ayakta kalabilmiş Bebek’teki Kavafyan konağı 18. asır Osmanlı konutuna canlı bir örnektir. Bu konakla ilgili bir çalışma için bkz. Hidayet Arslan, "Boğaziçi'nde 18. Yüzyıldan Kalma Bir İstanbul Evinin Durumu Hakkında Sanat Tarihi Bağlamında Yeni Değerlendirmeler", METU JFA 2014.1.5 (31:1): 97-117.

8 Serpil Başlılar Altun, "Geleneksel Türk Evleri, Kullanılan Yapı Malzemeleri, Yapı Elemanları ve Yapım Sistemleri”, (Yüksek Lisans Tezi KTÜ 2008): 193-201.

9 Allom, Türklerin evlerini taş bir temel üzerine ahşaptan yaptıklarını ve asla tamamen taştan yapmayı istemediklerini belirterek bunun sebebinin Türklerin kendi hayatları da dahil olmak üzere yeryüzünde bir şeyi sahiplenme arzularının bulunmayışı ve bireysel kullanımı için kalıcı bir konut inşasının dini olmadığını düşünmeleri olduğunu söylüyor (Thomas Allom, Constantinople and the Scenery of The Seven Churches of Asia Minor, 1, (Fisher, Son \& Co. London and Paris 1840): 32, 46); Benzer bir gözlem 16. asırda Busbecq tarafından yapılmıştır. Dikkate değer bir cümle: "Bir yolcu için han ne ise ev de Türkler için yağmur, soğuk, sıcak ve hırsızdan korunmaya elverişli olduğu 
pek çok yangın mahalleleri kısa bir sürede yok etmiştir. ${ }^{10}$ Uzun asırlar yangınlar sebebiyle kargir bina yapımı teşvik edilmekle birlikte evler yine ahşap yapılmıştır.

Yukarıda bahsedilen mimari unsurların pek değişmediğine dair işaretlere dönemin seyahatnamelerinde de rastlanmaktadır. ${ }^{11}$ Mesela D'ohsson'a göre evler genellikle bir veya iki katlıdır, üç katlı evler nadirdir. Zemin katta iki, üç büyük oda bulunmakta, esas oturma kat1 olan üst kata çıkan merdiven divanhaneye bağlanmaktadır. Eldem'in bahsettiği sofalı plan tipine uygun bir şekilde oldukça büyük olan divanhane etrafında odalar yer almaktadır. Yine özellikle, konaklarda ikiye bölünmüş olan üst katın bir tarafı kadınlara mahsustur. Zemin ise alt katlarda bile bir ayak eninde uzunlamasına tahtalarla döşenmiştir. Binalar umumen sadedir. ${ }^{12}$ Evlerin üstü kırmızı kiremitle örtülüdür. Evlerin pek çoğunda geneli ahşap olmasına rağmen mermer veya taştan kargir bir veya iki oda bulunması yangınlarda değerli eşyaları korumak içindir. Mutfak ve kilerler daima zemin kattadır. Her evde sarnıç ve kuyular bulunmaktadır. Burada D'ohson'a göre ahalinin oturduğu meskenlere "ev", ileri gelenlerin oturduklarına ise "konak" veya "hane" ismi verilmektedir.

1717-1718'de Türkiye'de bulunan Lady Montagu'nun Osmanlı evini tasvir eden bir mektubunda yapının planı ve yaşam alanlarının kullanılışı hakkında çok değerli bilgiler bulunmaktadır. Üzerinde çalışılan dönemden sadece altı yıl önce Türkiye'de bulunan Montagu'nun gözlemlerinden bir kaç önemli kısmı alıntı yaparak, onun Osmanlı konutunu tasviri faydalı olacaktır. Yalnız Montagu'nun bahsettiği yapı varlıklı ve devletin ileri gelenlerine ait konakların tasviridir. Bununla

nisbette muteberdir (Ogier Ghiselin De Busbecq, Türkiyeyi Böyle Gördüm, haz. Aysel Kurutluoğlu, (Tercüman 1001 Temel Eser): 21).

10 Büyük İstanbul yangını için bkz. Baron de Tott, 18. Yüzyılda Türkler, Türkler ve Tatarlara Dair Hatıralar, çev. Mehmet R. Uzmen, (Tercüman 1001 Temel Eser): 17, 19,70 .

11 Seyahatnamelerde özellikle 19. asır söz konusu olduğunda çok fazla bilgi bulunmakla birlikte burada 18. asır ve belki öncesi bir kaç seyahatnameden istifade, bu çalışma için daha uygun bulundu.

12 M. de M. D’ohsson, XVIII. Yüzyll Türkiye sinde Örfve Adetler, çev. Zehran Yüksel, (Tercüman 1001 Temel Eser): 125-127. Ayrıca tarihi Kayseri evlerinde selamlık ve haremlik için bkz. Faroqhi, a.g.e., 77-78. 
birlikte dahiliyeli-hariciyeli ibaresiyle sicillerde geçen konut örneklerine benzemektedir.

"Eminim ki, Türkiye'ye ait diğer seyahatnamelere bakıp da buradaki evlerin gayet acınacak bir şekilde inşa edildiğini zannedersiniz. Ben bu evlerden pek çoğunu gördüğüm için bilgince söyleyebilirim ki, yanılırsınız... Evlerin dışını süslemek adet değil. Hemen hepsi ahşap... Buradaki evler küçük veya büyük, iki klsımdan ibaret, aralarında dar bir geçitle bağlantı sağlanıyor. Birinci kısmın önünde geniş bir avlu ve etrafinda da üstü örtülü galeriler (sofalar olmalı) var ki, bu benim çok hoşuma gidiyor. Galerilerin bütün odalara bağlantısı var. Odalar umumiyetle büyük. Renkli camlardan yapılmış iki sıra pencereleri var. Iki kattan fazla evler çok az. Hemen hepsinin de galerisi var. Otuz basamağl geçmeyen merdivenler çok geniş. İşte bütün bu anlattıklarım ev sahibinin oturduğu kisımla ilgili. Kadınların oturduğu kismın da -ki buraya harem diyorlar- bir galerisi var, odalarm pencereleri buraya baklyor. Pencere sayısı diğer kısımlardaki kadar. Renkleri ve eşyaları itibariyle bu odalar daha ferah. İkinci siradaki pencereler çok alçak. Bu demir parmaklıkl pencereler tıpkı manastırlardaki gibi. Odaların zemininde hep Iran halıları serili. Odanın bir ucunda iki ayak yüksekliginde bir peyke var. Benim odamda iki tane. Bu peykelere sofa diyorlar. Üstünde diğer döşemelerden daha ăgır bir halı var. Etrafinda yarım ayak boyunda bir yükseklik var; üzeri evsahibinin zevkine göre ipek kumaşlarla örtülü... Ahşap tavan üzerine oyma veya boyama çiçek yapılmış. Duvarlardaki dolaplar bizimkilerden daha kullanışlı. Ikki pencere arasına da ufak raflar yapılmıs, üzerine kokular veya çiçek sepetleri konuluyor. Haremde en çok hoşuma giden şey, oda ortasındaki mermer fiskiye... Her evde bir hamam var...". ${ }^{13}$

Lady Montagu'nun verdiği bilgileri değerli k1lan en önemli özelliği kendisinin de açıkladığ 1 gibi kibar zümreye mensup bir hanım olarak Osmanlı ileri gelenlerinin mahremiyetine nüfuz edebilmiş olmasıdır. Telif eserlerde yer alan yukarıdaki gibi teferruatlı bilgilere arşiv kaynaklarında rastlamak mümkün olmamakla beraber daha kesin istatistiki bilgiler şeriyye sicillerinde görülmektedir. Dolayısıyla bu ça-

13 Daha fazla tafsilat için bkz. Lady Montagu, Türkiye Mektupları 1717-1718, çev. Aysel Kurutluoğlu, (Tercüman 1001 Temel Eser): 71-74. 
lışmada da 1724-1725 yılında, İstanbul Suriçi ${ }^{14}$ ile Eyüp ve Hasköy'de yapılan mülk satışları ele alınmıştır. ${ }^{15} \mathrm{Bu}$ bölgelere ait üç sicilin ${ }^{16}$ tamamı özetlenerek tablolaştırılmakla birlikte konut üzerine yapılacak başka çalışmalara destek olacağ 1 kanaatiyle bu çalışmada bütün mülk satışları değil sadece Osmanlı konutu incelenmiştir. ${ }^{17}$

Osmanlı döneminde ikamet olunan farklı konut tiplerinin tümünü belirtmek üzere menzil kelimesi kullanılmaktadır. ${ }^{18}$ İncelenilen kayıtlara göre Hicri 1137 (1724-25) y1lında konutlar, tahtani, fevkani ve tabakalı olarak kat sayısına ve dahiliye-hariciyeli yani iki ayrı k1sımdan ibaret olmalarına göre gruplanabilir. Yine başka bir tasnif ikamet mahalli / menzil altında yer alan yalı, yehudhane, köşk, konak, müteehhilin odası, çiftlik, bacalı menzil, kapıları ayrı bitişik menzil şeklinde görülmektedir. Mekan bölümlemesi ve işlevsellik sofa yanında yine avlu ile sağlanmaktadır. Pek çok konutun avlusu olmakla birlikte ayrıca bahçeli konutların mekansal olarak daha büyük olanlarda bulunduğu genellenebilir.

Sıradan bir Osmanlı konutu altlı üstlü iki alanda oda ve sofaları, genel olarak alt kisımda avluda bir tuvalet, su kuyusu, mutfak, bazen mahzen, bazen ayrıca bodrum, ahır gibi müştemilattan oluşmaktadır. Daha büyük konutlarda ise ki oda sayıları fazladır, buna göre sofalar tek bir katta iki adet de olabilir. Yine klasik evlere göre cihannüma, tahtapuş, kiler, zir-i zemin (bodrum), hamam gibi bölümlemeler yer alır.

14 Suriçi bölgesi İstanbul surlarının çevrelediği alanı kapsamaktadır. Elbette Sur ile deniz arasında olan kısımlar da İstanbul Suriçi bölgesi kapsamında kullanılmaktadır. Esasen İstanbul denildiğinde kastedilen Suriçi bölgesidir. Hem telifatta hem de arşiv belgelerinde ana yerleşim bölgeleri İstanbul, Boğaziçi, Galata, Üsküdar, Kadıköy ve benzeri şekilde ayrımlanır. Ancak bugünün kullanılışıyla karışmaması için "İstanbul Suriçi” olarak nitelenmek zorunda kalınmıştır.

15 Mülk satışları, satışı yapılan mülkün olduğu yerdeki mahkemede yapılmak zorunda olmadığından Suriçi mahkemelerinden olan Bab ve Ahi Çelebi mahkemelerinde Eyüp ve Hasköy' dahil pek çok farklı yerdeki mülklerin satış kayıtları yer almaktadır.

16 Bunlar; İstanbul Bab Mahkemesi (2) 135 (100 varak), İstanbul Ahi Çelebi Mahkemesi (7) 124 (128 varak) ve aynı mahkemenin 125 (146 varak) numaralı defterleridir.

17 Hazırlanan tablo, bu derginin makale başı azami sözcük sınırını çok fazla aştığı için yazıya eklenememiştir.

$18 \mathrm{Bu}$ makalede menzil yerine -tam olarak karşılamamakla birlikte- konut kelimesi tercih olunmuştur. 
Sayısal değerlendirmelere geçmeden önce alım-satım hüccetlerinde aynı evin muhtelif zamanlarda satışlarına rastlandığı belirtilmelidir. Bunun sebeplerinden biri, bir konutun genellikle vefat sonrasinda hissedarları tarafindan hisselerinin farklı zamanlarda satılmasındandir ${ }^{19}$ ki bu durumda konut bir kişi tarafından tüm hisseleri satın alınarak tek sahipli hale gelmektedir. Yine alıcı tarafindan başkasına kısa süre içinde tekrar satılması kar amaçlı olanları akla getirebilir. Bazı satışların ise aslında şeklen gerçekleştiği görülmektedir. Bu tip satışlar yakın akrabalar arasındadır. Menzil satışlarında tekrar satım işlemi gören ve tespit olunabilen aynı menziller ( 7 adettir) ve bunlar tek menzil olarak ele alınmıştır. Nadiren olsa da tek bir celsede birden fazla mülkün satıldığı görülmektedir. Mesela bir kayıtta birbirine bitişik 2 menzil tek seferde satılmıştır. ${ }^{20}$ Yine başka bir kayıtta, 4 ayrı birimden 2 adedi dahiliye-hariciyeli, 1 adedi tahtani olan yehudhane, diğer 1 adedi ise yalının müştemilatından sayılabilse de satışta müstakilen belirtilen tahtani yapılar topluluğudur. ${ }^{21}$ Dolayısıyla burada da çalışma Suriçi yarımadasıyla sınırlandığından Kanlıca'daki yalı ve müştemilat sayılara dâhil edilmemiştir. Şu durumda değerlendirmeye kalan örnek 122 adettir.

Örnek kayıtlar defterdeki satış tarihlerine göre şöyle sıralanmaktadır.

Muharrem (20.09-19.10.1724): 3, Safer (20.10-17.11): 7, Rebiü'l-evvel (18.11-17.12): 8, Rebiü'l-ahir (18.12.1724-15.01.1725): 12, Cemaziye'l-evvel (16.01-14.02): 12, Cemaziye'l-ahir (15.02-15.03 ): 5, Receb (16.03-14.04 ): 16, Şaban (15.04-13.05 ): 18, Ramazan (14.05-12.06 ): 3, Şevval (13.06-11.07 ): 8, Zi'l-kade (12.07-10.08 ): 20, Zi'l-hicce (11.08-08.09): 10.

Satışlar ilkbahar aylarıyla artmış, Ramazan'ın girmesiyle düşmüş ve sonra tekrar yükselmiş̧ir. Konutların sınır ve nitelikleri belirtilenler çoğunlukta olmakla birlikte malumü'l-hudud ve'l-müştemilat ibaresi ile hiç bir niteliği belirtilmeyen satış sayısı 15 adettir. Bazen fevkani ve tahtanilik belirtilip oda sayısı belirtilmemektedir. Bunlardan

19 İŞS., 7/124-134b.2; İŞS., 7/125-65b.3

20 İŞS., 7/125-55a.3.

21 İŞS., 2/135-30b.2. 
bir kısmında fevkani ve tahtanilik belirtilip (fevkani ve tahtani büyüt-i adide ve havlu) oda sayısı belirtilmediğinden fevkani veya tahtani konutlar içerisine dâhil edilmiştir. Nitelikleri belirtilmeyenler arasında 1 yalı, 1 yehudhane, 1 mütehhilin odası bulunmaktadır. Görüldügü kadarıyla yalılar dâhiliyeli-hariciyeli, yehudhane ve mütehhilin odaları tahtani menziller grubuna girmekle birlikte aşağıdaki toplamlara bunlar dâhil olunmamıştır.

Hariciye ve dâhiliye kelimeleri ile kast olunanın haremlik ve selamlık olmalıdır. Bunlar iç ve dış kısımlar olarak isimlendirilen bir evin belirli odaları olabileceği gibi daha büyük evlerde bölümleme yerini birleşmeye yani birden fazla evin tek bir kütle içerisinde yer almasına da bırakabilirdi. Yani bir tek bina altında sofa ile ayrılmış iki alan olabileceği gibi iç avlu ile ayrılmış iki müstakil ve fakat birbirine bir dehliz veya sofa ile bağlı bileşik alanlar olmalıdır. Nitekim bazı evlerin iki ayrı giriş kapısı ve orta avluları bunu gösterebilir. ${ }^{22} \mathrm{Bu}$ tip evlerin Hicri 1137 (1724-25) yılı sayısı ele alınan örneklere göre 34'dür.

İki katlı veya altlı üstlü iki bölümlü fevkani ve tahtani konutların sayısı ise 51'dir. Dâhiliye-hariciyeli menziller çoğunlukla fevkani yapılardır. Tek katlı yani tahtani konutların sayısı 8 'dir. Tabaka-i ulya, vusta ve süfla ibaresi ile tasvir olunan muhtemelen 3 katlı konut say1s1 11'dir. Tabaka-i ulya, tabaka-i vusta ve tabaka-i süfla terimlerinin asma veya tam kat olduğu kesin olmamakla birlikte üst, orta, alt kısım şeklinde üç ayrı katı ifadeyle bu konutların üç katlı yapılar içerisine konulabilmesi muhtemeldir. Ayrica menzil olarak nitelendirilen 2 yehudhane, 1 müteehhilin odası bulunmaktadır.

Konutların bina olundukları arsa miktarları da bazı kayıtlarda bulunmaktadır ki bunlar aşağıda yer almaktadır. Takribi olarak 1 mimar ziraı $76 \mathrm{~cm}$ olarak kabul edilirse bazı konutların inşa edildikleri alanlar şöyledir:

194,56 $\mathrm{m}^{2}$ arsa üzerine haremlik ve selamlıkl1, toplamda fevkani 3 oda, 2 sofa, dehliz, alt katta dehliz, tuvalet, küçük bir hamam, su kuyusu, mutfak, avlu ve bir miktar bahçeli ev. ${ }^{23}$

22 Eldem, Türk Evi, 20.

23 İşS., 7/124-7a.2. 
Takriben $95,7 \mathrm{~m}^{2}$ arsa üzerinde üst katta 2 oda, 1 sofa, alt katta tuvalet, 1 oda ve bahçe. ${ }^{24}$

$2346 \mathrm{~m}^{2}$ arsa üzerinde haremlik ve selamlıkl1, üst katlarda toplam 6 oda, 1 mabeyn odası, sofa alt katlarda mutfak, su kuyusu, bahçeli. ${ }^{25}$

17,2 metre uzunluğunda 15 metre eninde $357.2 \mathrm{~m}^{2}$ arsa üzerine bina olunmuş tahtani 4 oda, 1 selamlık sofası, 1 mutfak, çocuk eğitilecek bir oda ve tahminen $68 \mathrm{~m}^{2}$ meyveli ve meyvesiz ağaçlı bahçe, 2 sarnıç, 1 berber dükkanı, 1 attar dükkanı, taş duvarlı 3 mahzen, menzilin dâhilinde kazılarak çıkarılmış 2 masura suyu içeren yehudhane denilen menzil. ${ }^{26}$

13.6 metre uzunluğunda, 5.7 metre eninde $102,6 \mathrm{~m}^{2}$ arsa üzerine bina olunmuş fevkani 1 oda, 1 sofa, tahtapuş, tahtani 1 oda, 1 sofa, kenif, avlu. ${ }^{27}$

Konutların su ihtiyacı için genellikle kuyular kullanılmaktadır. 122 örnekten 70 menzil su kuyuludur ve bazılarında birden fazla kuyu bulunmaktadır. Ayrıca bir kısmında kanall1 $1^{28}$ tatlı su mevcutur. Menzillerin bazılarında çift olarak toplam 46 bahçe bulunmakta, çift bahçeli olanlar tek sayıldığında bu sayı 30 olarak çıkmaktadır. Yine, 63 menzilin en az bir avlusu olup bazılarında birden fazla avlu vardır.

$\mathrm{Bu}$ sonuçlardan yola çıkarak Hicri 1137 (1724-25) yılında İstanbul'da bulunan konutların çoğunlukla iki katlı ve hatta haremlik ve selamlık kısmı bulunan 34 menzil göz önüne alındığında küçük yapılar olmadığı sonucu çıkarılabilir ki Anadolu'nun diğer şehirlerine göre yapılaşmanın çok katlılığına sebep olarak İstanbul'un başkent ve bir kültür, ticaret merkezi oluşu, 18. asırda bütün tedbirlere rağmen

24 İŞS., 7/124-22b.2.

25 İşS., 7/124-79a.1

26 İşS., 7/125-6b.1.

27 İŞS., 7/125-13a.2.

28 Genel olarak "kanavat-1 müsennatına tebaiyyetle bir masura (nısf masura vs.) ma-i leziz-i cari" olarak sicilerde geçen ibareler menzillere, künklerle, döşenmiş borularla su getirilmesini ifade etmektedir. 
yoğun göç alan eski bir yerleşim bölgesi olarak arsaların azalması gösterilebilir. $^{29}$

Menzillerin fiyatları ortalama 50 kuruştan 6000 kuruşa kadar değişmektedir. Fiyatların farklılığını etkileyen pek çok unsur bulunmakla birlikte özellikle yalılar en pahalı olanlardır. İkinci olarak yüksek fiyatla satılanlar dâhiliyeli-hariciyeli menzillerdir. En düşük fiyatlı olanları tahtani ve bir odalı olanlar oluşturmaktadır. Yalnız, aile içi satışların bir kısmında fiyatların sembolik olduğu göz önünde tutulmalıdır. Mesela aile içinde el değiştiren veya tek kişi üzerinde birleştirilmiş hisseli menziller oda sayılarına göre oldukça düşük fiyatlıdır. Elbette menzilin bulunduğu mahalle, arsa genişliği, arsanın mukataalı olup olmaması, bahçeli, avlulu oluşu kadar hamam, camekan, köşk, havuz, tatlı su bulunması gibi unsurlar da fiyatı etkilemektedir. Yeterli veri elde edilinceye kadar mülk fiyatlarına göre müreffeh, orta halli mahalleler şeklinde tespit yapılması doğru olmamakla birlikte en azından yalıların en yüksek fiyatlara sahip olduğu söylenebilir.

Mesela, 17 Şaban 1137/ 1 Mayıs 1725 tarihinde 5000 kuruşa satılan bir yalının özellikleri şöyledir: Eyüp Şah Sultan mahallesinde, etrafı Hüsrev-zade mülkü, Şah Sultan camii, leb-i derya, tarik-i amla çevrili, hariciyesinde tabaka-i ulyada 4 oda, 1 mabeyn odası, 2 sofa, dehliz, kenif vustada, 6 oda, dehliz, kenif, suflada 1 matbah, kebir ahır, havlu, dâhiliyede deniz tarafında 6 oda, 3 sofa, havuz ve şadırvanlı 2 kebir divanhane, kenif, meyveli ve meyvesiz ağaçlı bahçe, 1 köşk, hariciye tarafinda 4 fevkani oda, 1 sofa, 2 camekan, 2 halvetli hamam, 1 kiler, 1 kebir matbah, kenif, 4 masura ma-i lezizi muhtevi yalı denilen menzil ile kayıkhane. Yalının sahibi Akbıyık mahallesinde sakin iken vefat eden Ser-etibba-i hassa merhum Nuh Efendi' dir. Oğlu Halep valisi Ali Paşa ve kardeşi sabık İzmir kadısı Evliya Yusuf Efendilerdir. Nuh Efendi'nin ölümüyle 12 sehimden beş sehmin sahibi olan oğullar

29 18. asırda Konya'da bulunan menziller çoğunlukla tahtanidir. 105 örnek üzerinde yapılan bir çalışmada 88 adet menzil tahtani olup dahiliye-hariciyeli sadece 4 menzil bulunmaktadır (Hicran Hanım Halaç, “45 Numaralı Konya Şeriyye Sicil Defterindeki Menzil Satışları Işı̆̆ında Yol Ağları ve Kat Sayısına Göre Konut Tipolojisi (17141715)", Turkish Studies, 7/3, (Ankara, 2012): 1443). Bu makalenin derlendiği sicil için bkz. İzzet Sak, Cemal Çetin, 45 Numaralı Konya Şer'iye Sicili (1126-1127 / 1714 1715) (transkripsiyon ve dizin), (Selçuklu Belediyesi Kültür Yayınları: 28, Konya, 2008). 
hisselerini diğer yedi sehmin sahibi, valideleri Safiye Hatun'a $1500 \mathrm{ku}-$ ruşa satmışlardır. Satım sırasında Kabasakal mahallesinde oturan Safiye Hatun da, yalıyı Ayişe Hanım bint Şatırbaşı Hasan'a 5000 kuruşa satmıştır. ${ }^{30}$ Bir başka örnek menzil de yine hariciye-dâhiliyeli olanlardandır. Üskübi mahallesindeki hariciyesi fevkani 4 oda, cihan-nüma, 1 sofa, dehliz, kenif, tahtani 1 oda, ahır, su kuyusu, havlu, dâhiliyesi 5 oda, 2 sofa, 1 tahtapuş, 1 matbah, 1 hamam, 1 kargir demir kapıll camekan, 1 mahtab, su kuyusu, meyveli ve meyvesiz ağaçlı bahçeyi muhtevi mülk menzil 3500 kuruşa satılmıştır. ${ }^{31}$

Sonuç olarak geleneksel Osmanlı konutu denildiğinde akla gelen yapının çağdaş çalışmalarda belirtilen mimari unsurlarıyla ${ }^{32}$ eldeki tarihsel veriler mukayese edildiğinde aralarında büyük bir fark olmadığı gözlemlenmektedir. Esasen geleneksel konutun yapısal birimleri hakkında mimar ve sanat tarihçileri tarafından mütemmim bilgiler veren eserler ortaya konulmuştur. Eksik olan ise bu verilerin tarihsel zamanlarda gerçekten mevcut olanlarla mukayese ile teyit edilmesi ve yıllara göre yapının çeşitli unsurlarının tabir caizse, fotoğraflanmasıdır. $\mathrm{Bu}$ noktadan bakıldığında tarihsel konutlara dair çalışmaların görece sınırlı olduğu söylenebilir. Nitekim bu çalışmada da örneklenen konutlar bir yıl içinde satım işlemi için kadılığa gidilerek kayda geçenlerden oluşmaktadır. Belki bir sonraki yıl satım işlemi daha fazla veya az yapılmış olabilir. Mesela salgın hastalıkların, savaşların ve sair afetlerin ortaya çıktığı zamanlarda ölüm oranlarının artması bile ev satışlarında etkin olabilir. Ayrıca konutlar kolayca ve sıklıkla el değiştirmediğine göre daha uzun aralıklar veya hiç olmazsa mesela, bir padişah döneminde konut satımı incelenerek gerçek anlamda ve daha kesin verilerle yapısal yerleşim tespit olunabilir. Bununla birlikte bu neviden çalışmaların fazlalaşmasıyla veriler artacak ve ileride daha bütünlüklü çalışmaların önü açılmış olacaktır.

30 İŞS., 2/135, 34b.4.

31 İŞS., 2/135, 68b.2.

32 Bu hususta Sedad Hakkı Eldem'in Türk Evi isimli eserinde bol miktarda örnek bulunmaktadır. 


\section{Kaynakça}

\section{Şeriyye Sicileri}

İstanbul Bab Mahkemesi 135, İstanbul Ahi Çelebi Mahkemesi 124 ve 125.

\section{Telif Eserler}

Allom, Thomas. Constantinople and the Scenery of The Seven Churches of Asia Minor. London and Paris: Fisher, Son \& Co., 1, 1840.

Altun, Serpil Başlılar. “Geleneksel Türk Evleri, Kullanılan Yapı Malzemeleri, Yapı Elemanları ve Yapım Sistemleri” Yüksek Lisans Tezi, Karadeniz Teknik Üniversitesi, 2008.

Arel, Ayda. Onsekizinci Yüzyll İstanbul Mimarisinde Batılılaşma Süreci. İstanbul: İTÜ Mimarlık Fakültesi, 1975.

Arslan, Hidayet. "Boğaziçi'nde 18. Yüzyıldan Kalma Bir İstanbul Evinin Durumu Hakkında Sanat Tarihi Bağlamında Yeni Değerlendirmeler." METU JFA 2014.1.5, 31, 1, 97-117.

Busbecq, Ogier Ghiselin de. Türkiyeyi Böyle Gördüm. Haz. Aysel Kurutluoğlu. Tercüman 1001 Temel Eser.

Celal, Esad. Türk Sanatı, İstanbul: Türk Ocakları Merkez Neşriyatı, 1928.

Cerasi, Maurice. "The Formation of Ottoman House Types: A Comparative Study in Interaction with Neighboring Cultures", Muqarnas, 15 (1998): 116-156.

Çolak, Ali. 1868 nolu Trabzon Şeriyye Siciline Göre Kentin Sosyal ve Ekonomik Hayatı (1703-1705), Yüksek Lisans Tezi, Karadeniz Teknik Üniversitesi, 1997.

D’ohsson, M. de M. XVIII. Yüzyll Türkiye'sinde Örf ve Adetler. Çev. Zehran Yüksel. Tercüman 1001 Temel Eser.

Eldem, Sedad Hakkı. Türk Evi Osmanlı Dönemi 1. İstanbul: Türkiye Anıt Çevre Turizm Değerlerini Koruma Vakfi, 1984.

Faroqhi, Suraiya. Men of Modest Substance, House Owners and House Property in Seventeenth-Century Ankara and Kayseri. Cambridge: Cambridge University Press, 2002.

Gabriel, Albert. “Türk Evi.” Arkitekt Dergisi 5-6, (1938): 149-154.

Halaç, Hicran Hanım. “45 Numaralı Konya Şeriyye Sicil Defterindeki 
Menzil Satışları

Işığında Yol Ağları Ve Kat Sayısına Göre Konut Tipolojisi (17141715)." Turkish Studies, 7/3, (2012): 1437-1448.

Karacaoğlu, M. Faruk. 1765-1768 Yılları Arasında Konya'da Sosyal ve Ekonomik Hayat, (59 Numaralı Konya Şer'iye Siciline Göre), Yüksek Lisans Tezi, Selçuk Üniversitesi, 2008.

Kuban, Doğan. Türk Hayat'lı Evi. İstanbul: Eren Yayıncılık, 2013.

Lady Montagu. Türkiye Mektupları 1717-1718. Çev. Aysel Kurutluoğlu. Tercüman 1001 Temel Eser.

Nureddin İbrahim. "Yeni Ankara'da Eski Türk Evleri." Yeni Kitab 9, (1928): 28-32.

Sak, İzzet ve Cemal Çetin. 45 Numaralı Konya Şer'iye Sicili (11261127 / 1714-1715) (transkripsiyon ve Dizin, Selçuklu Belediyesi Kültür Yayınları: 28, Konya, 2008.

Sarıalioğlu, Ceren. Historiyografik Bir Sorunsal Olarak: "Türk Evi" (1928-1995), Yüksek Lisans Tezi, Yıldız Teknik Üniversitesi, 2008.

Tott, Baron de. 18. Yüzyılda Türkler, Türkler ve Tatarlara Dair Hatıralar. Çev. Mehmet R. Uzmen. Tercüman 1001 Temel Eser.

Tuztaşı, Uğur. Koruma ve Tarihsel Açıdan İdealleş[-tiril-]miş "Türk Evi"nin Arkeolojisi: Osmanl Evinin Fragmanlarl ve Tipolojik Elemanları, Doktora Tezi, Mimar Sinan Güzel Sanatlar Üniversitesi, 2009. 